Reviews in Digital Humanities •

\title{
Review: The Museum of Portable Sound
}

\section{Rebecca Gates ${ }^{1}$}

${ }^{1}$ Independent musician, curator, and audio artist

Published on: $\operatorname{Sep} 13,2021$

License: Creative Commons Attribution 4.0 International License (CC-BY 4.0) 


\section{Project}

The Museum of Portable Sound

\section{Project Director}

John Kannenberg, Director and Chief Curator, The Museum of Portable Sound

\section{Project URL}

https://www.museumofportablesound.com

\section{Project Reviewer}

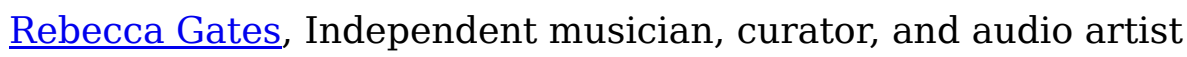

\section{Project Overview}

\section{John Kannenberg}

The Museum of Portable Sound (MOPS) is an institution aimed at a general audience that originated as part of my $\mathrm{PhD}$ research at the University of Arts London in November 2015. It is a portable museum on a single mobile phone made up of sounds: 325 field recordings, mostly made by me over the past two decades, arranged into 30 themed galleries according to popular museum taxonomies including "Natural History," “Science \& Technology," “Architecture \& Urban Design," and "Art \& Culture.” There was no app to download.

Originally, visitors booked an appointment to meet with me in person and brought their own headphones. This absurdist rule meant visitors were required to set aside time to listen-a rarity in contemporary urban life. Visitors were presented with the MOPS mobile phone, a map of the museum's content conceptualized as an architectural space-like infographic, and a printed Gallery Guide containing object labels and other didactic information usually found on museum walls. Visitors listened to the museum as long as they wanted. Often we had lengthy conversations about the role of sounds in culture and in the visitor's own life.

In 2020, after finishing my $\mathrm{PhD}$ and with the onset of the COVID-19 pandemic, MOPS began offering online visits via video chat using a PDF Online Visitor Guide. Visitors now request to listen to the sounds, which I play to the video chat from the same mobile phone. This format allows for conversations as was part of the original inperson visits. Online visitors are charged an admission fee. While there is still no MOPS app, MOPS has produced one free online exhibition. MP3@25, which explores 
the cultural impact of the MP3 digital audio format, opened July 14, 2020, the MP3's 25th anniversary.

Originally limited to people located in London (or anywhere I traveled), online visits have brought MOPS to a new global audience. There have been 1,455 total visitors, 88 of those occurring since the pandemic began in 2020. That same year, I began a partnership with the New London Little Theater that introduced the museum to a small town in Minnesota-a model that can be used to establish more satellite branches around the world. MOPS does not currently receive funding but must soon in order to operate sustainably. The project has been featured on $\underline{\mathrm{BBC}} 4$ Television, $\underline{\text { Atlas }}$ Obscura, Londonist.com, and the Public Work podcast, among others.

\section{Project Review}

\section{Rebecca Gates}

The Museum of Portable Sound (MOPS) originated as a listening practice in contemporary museums during visiting hours. It is currently structured as a collection of field recordings by curator John Kannenberg, organized as exhibition galleries on a single mobile phone. Associated objects corresponding to a museum experience include a gallery map, printed monograph, and, as in a gift shop, a coloring book, deck of sound cards, totes, and t-shirts available for sale. The collection is experienced by a single user, in the presence of Kannenberg. Initially, visits occurred in person, though access has expanded online via website, social media, and allied art spaces, while maintaining a one-on-one listening experience at its core.

As the project has evolved it has provided an arena for inquiry into how institutions affect content and how sound, as a material, inhabits and challenges the structure of a museum. This intentional transgression, via foregrounding of aural experience, of the pervasive secondary role sound plays in exhibitions is part of a discipline-wide inquiry into what sound art actually is. Curating the field recordings within a museum framework offers listeners a node to consider questions including: "What is sound as art?" "Where in an art experience is sound positioned?" "When is sound art?" As Sanne Krogh Groth and Holger Schulze note, "They [Kannenberg, Meelberg, Cobussen, et al.] position sound art actually in this larger context of everyday life and its manifold issues of contemporaneity" (15).

MOPS offers a focused yet dynamic conceptual space to explore sound technologies as well as sounds themselves. The project provides an introduction to multiple forms of 
physical and digital media and its evolution and devolution. Furthermore, it incorporates investigation of these forms using technology itself as an orientation point for the exhibition MP3@25.

MOPS raises a number of critical questions about mobility, materiality, and portability: Is the project affected if we bring all qualities of museums to bear beyond architectures of exhibition and interaction? Are there ways to avoid hazards that befall museums such as access and equity? At what point does the mantle of a museum limit the expository potential of the sounds themselves or the opportunity to expand understanding of sound's materiality? What might occur if the ineffable qualities of sound, and its own mobility as waves were a point of portable inquiry? How is sound a mediator between object (all museum sounds are recorded) and ear? And how can we bring awareness to the active relationship of corporeal listening and synthesis of sounds?

The evolution of the museum through various technological mediums is a compelling way of reframing the materiality of sound. The project plays with sound as media and media as sound, integrating participants in partnership with technology through the act of listening (and vice versa), operational physicality, and sonic wayfinding. In an era of nomadic curating, MOPS offers an inviting and rigorous project for investigating the many facets of a young and quickly evolving culture of sound and listening.

\section{Works Cited}

Groth, S. and Schulze, H. "Sound Art: The First One Hundred Years of an Aggressively Expanding Art Form. The Bloomsbury Handbook of Sound Art, edited by Sanne Krogh Groth and Holger Schulze. Bloomsbury, 2020, pp. 1-20. 